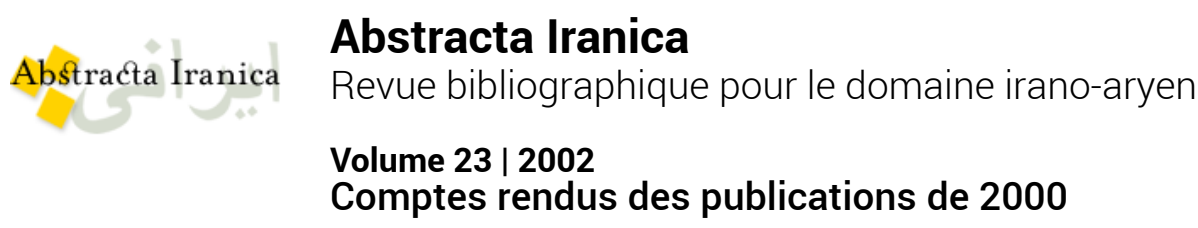

\title{
PRÉFACE - Abstracta Iranica 23 - 2000
}

\section{Christophe Balaÿ}

\section{(2) OpenEdition}

Journals

Édition électronique

URL : http://journals.openedition.org/abstractairanica/35950

DOI : 10.4000/abstractairanica.35950

ISSN : 1961-960X

Éditeur :

CNRS (UMR 7528 Mondes iraniens et indiens), Éditions de l'IFRI

Édition imprimée

Date de publication : 15 mai 2002

ISSN : 0240-8910

\section{Référence électronique}

Christophe Balaÿ, «PRÉFACE - Abstracta Iranica 23 - 2000 », Abstracta Iranica [En ligne], Volume 23 | 2002, mis en ligne le 08 février 2010, consulté le 25 septembre 2020. URL : http://

journals.openedition.org/abstractairanica/35950 ; DOI : https://doi.org/10.4000/abstractairanica 35950

Ce document a été généré automatiquement le 25 septembre 2020.

Tous droits réservés 


\title{
PRÉFACE - Abstracta Iranica 23 - 2000
}

\author{
Christophe Balä̈
}

1 En présentant le vingt-troisième volume des Abstracta Iranica pour décrire l'année 2000 de la bibliographie des études iraniennes, passage pour une bonne partie du monde au XXI ${ }^{\mathrm{e}}$ siècle, même pour l'Iran, qui fêtait pourtant l'année 1379 de l'hégire solaire, signe de la singularité de cette culture et de cet héritage, il faut saluer et remercier chaleureusement les trente-quatre collaborateurs de la revue pour leur inlassable fidélité et pour le service si précieux qu'ils rendent année après année à la communauté scientifique ainsi qu'à tous ceux qui s'intéressent à l'Iran, ses habitants, leur histoire, leurs cultures et leurs langues, qu'il faut décliner au pluriel tant est riche et varié le champ d'étude que constitue la civilisation iranienne.

2 Une première lecture globale de ce numéro 23 permet de souligner une constante dans la répartition des volumes des diverses sections bibliographiques : en première position se tient l'histoire ancienne et moderne avec environ cent-cinquante entrées ; vient en second la littérature persane classique et moderne avec une centaine d'entrées; ces deux grands secteurs constituant à eux seuls les deux-tiers de ce numéro 23. Le dernier tiers se répartit en trois parts à peu près égales entre bibliographie / linguistique, sciences sociales et islam / soufisme. Doit-on voir dans cette proportion le signe d'une extrême vitalité des domaines historique et littéraire, ou bien le plus grand dynamisme des collaborateurs dans ces deux grands champs d'étude? En tout état de cause, il faut plaider pour une plus grande attention au domaine des domaines des sciences sociales, d'une importance capitale pour la compréhension des réalités socio-culturelles, sociopolitiques et économiques dans un pays en pleine mutation.

3 On notera enfin, avec regret, la quasi disparition des rubriques touchant à l'Asie centrale, qui avaient été accueillies dans Abstracta et qui en ont été retirées sans autre forme d'explication par celui qui en avait pris la responsabilité. Ce sera sans doute l'occasion d'envisager un nouveau mode de coopération avec l'IFEAC, pour optimiser les moyens qui sont à notre disposition dans l'aire géo-culturelle qui est la nôtre et que 
la réforme des conseils scientifiques de nos instituts dans le cadre d'un pôle régional incite à regrouper pour des actions communes.

Il faut, pour finir, remercier particulièrement le CNRS et l'équipe Monde Iranien d'avoir bien voulu mettre à nouveau à la disposition d'Abstracta un secrétariat parisien, pour un temps partiel, en affectant à cette responsabilité Poupak Rafii Nejad que nous saluons ici et remercions pour sa collaboration. Elle a pour tâche principale la coordination du travail des collaborateurs et la communication de Téhéran avec l'extérieur. Elle a enfin mission de contribuer avec l'aide de tous à la constitution d'un comité scientifique, plus que jamais nécessaire à l'édition d'Abstracta. Les ultimes remerciements, et non les moindres, vont à l'équipe des publications de l'IFRI, Dominique, Annette et Shadi qui, pour la troisième fois consécutive, ont pris en charge l'édition de la revue avec un soin admirable.

INDEX

Thèmes : Avant propos

\section{AUTEUR \\ CHRISTOPHE BALAŸ}

Directeur des Abstracta Iranica 